\title{
Effect of a calorie-restricted, low-glycemic diet and exercise with omega-3 fatty acid and vitamin D supplementation on the risk of metabolic syndrome
}

\author{
Robert B Thomas, Amy Curtis, Laelie A Snook and Kelly A Meckling* \\ Department of Human Health and Nutritional Sciences, University of Guelph, Guelph, Ontario, Canada
}

\begin{abstract}
The Metabolic Syndrome (MetS) is of growing concern worldwide. Therefore, it is important to determine interventions that mitigate its risk factors. This pilot study investigated whether the supplementation of omega-3 fatty acids and vitamin D to a low glycemic index, moderate protein, calorie-restricted diet and regular exercise regimen could further improve the health benefits of the diet and exercise intervention alone. Following eight weeks of lifestyle modification, both groups demonstrated decreased body weight, blood pressure and body mass index, while only the supplemented group showed a decreased resting heart rate. There were no changes in fasting blood glucose, insulin or triacylglyerol with either treatment; however reduced HbA1c was observed only in the supplemented group. While neither heart rate nor HbA1c measures are specific risk factors for MetS, they both indicate improved metabolic health, suggesting that vitamin D and omega-3 supplementation in the background of healthy diet and exercise merits further investigation.
\end{abstract}

\section{Introduction}

The prevalence of the Metabolic Syndrome (MetS) is nearing $30 \%$ worldwide [1]. The definition of MetS continues to evolve, but is associated with the dysregulation of metabolic measures associated with obesity [2]. Given the severity of the associated co-morbidities (stroke, type 2 diabetes), considerable effort is being made to reduce adiposity and risk factors of MetS [3,4].

Weight loss can be induced by diets consisting of: calorie restriction, low glycemic index, or high-protein [5-9]. Sufficient calorie restriction can cause endogenous fuel usage leading to weight loss [10]. Low glycemic index foods are more slowly absorbed, leading to prolonged insulin release $[11,12]$, a tempered glucose response and improved TAG and cholesterol profiles [11]. Substituting carbohydrates with protein has been associated with improved glucose tolerance, blood pressure, and HDL-cholesterol [5,7,13-15], although a direct effect on MetS remains inconclusive [15].

Increased energy expenditure can also improve markers of MetS [16]. Exercise can cause weight loss with added benefits including: targeted abdominal fat mass loss [17], reduced blood lipids [18] and improved insulin sensitivity.

We have previously reported a diet and exercise intervention improves the symptoms of MetS [5]. However, what remains poorly understood is the effect of nutritional supplementation on this background, specifically omega-3 $(n-3)$ and vitamin $D$. The TAGlowering effect of $n-3 s$ is well-established [19-22]. In addition, $n-3$ supplementation can improve insulin sensitivity and glycemic control in rodent models [13,23], although equivocal in humans [24,25]. An inverse association between vit $\mathrm{D}$ status and abdominal adiposity has been demonstrated for hypertriacylglyceridemia and hyperglycemia $[26,27]$, possibly by enhancing insulin release [26-29].

Individually, the above interventions improve risk factors of MetS. Therefore, we performed a pilot study to determine whether $\mathrm{n}-3$ and vit
D supplementation with a hypocaloric, low-glycemic index, moderate protein diet [9] and exercise program could show even greater improvements on remediating the risk factors of MetS.

\section{Methods}

\section{Recruitment and screening}

This study was approved by the Research Ethics Board at the University of Guelph (REB\# 11JA022) and registered as a clinical trial at clinicaltrials.gov (NCT01326442). Male and female participants between 18 and 65 years of age were recruited from April to July 2011 from the University of Guelph and the City of Guelph community. Recruitment materials consisted of advertisements in the local newspaper, online classified advertisements on kijiji.ca, posters in public places and doctor's offices. Study entry for participants was staggered and they were screened in batches monthly. Ninetyeight people expressed interest in participating via email or by telephone and were interviewed by the study coordinator and asked to complete an initial screening questionnaire. Of the original 98 interested participants, 55 qualified for an in-person screening session. At this appointment, potential participants completed a health questionnaire, and were provided with a detailed written explanation of the study protocol, including potential benefits and risks to themselves for participating [30]. Qualified personnel were available to answer any additional questions. After providing informed consent,

Correspondence to: Kelly A Meckling, PhD, Department of Human Health and Nutritional Sciences, University of Guelph, Guelph, Ontario, Canada, Tel: 5198244120/53742; Fax: 5197635902; E-mail: kmecklin@uoguelph.ca

Key words: calorie restriction, exercise training, low glycemic index, metabolic syndrome, omega-3, vitamin D

Received: July 13, 2017; Accepted: August 28, 2017; Published: August 29, 2017 
Thomas RB (2017) Effect of a calorie-restricted, low-glycemic diet and exercise with omega-3 fatty acid and vitamin D supplementation on the risk of metabolic syndrome

anthropomorphic measures (height, body weight, waist circumference, hip circumferences, body composition), blood parameters (fasting glucose, insulin, glycosylated hemoglobin (HbAlc), CRP, total cholesterol, HDL-cholesterol, and serum TG), resting heart rate and blood pressure and were measured to determine whether the participant met the inclusion criteria, namely central adioposity cutoff and 2 of 4 additional criteria for MetS (2005 IDF definition of MetS: waist circumference $\geq 94 \mathrm{~cm}$ (male), $\geq 80 \mathrm{~cm}$ (female); TAG $\geq 1.7 \mathrm{mM}$; blood pressure $\geq 130 / 85 \mathrm{~mm} \mathrm{Hg}$; HDL-cholesterol $\leq 1.03 \mathrm{mM}$ (male), $\leq 1.29 \mathrm{mM}$ (female); glucose $\geq 5.6 \mathrm{mM}$ [30]). Participants were excluded if they were currently smoking, were pregnant or had been pregnant or breastfeeding in the past 6 months, currently taking anticoagulants, aspirin, magnesium containing antacids, or omega- 3 fatty acid and vitamin $\mathrm{D}_{3}$ supplements at dosages comparable to what the study protocol was providing. Participants who were consuming omega-3 fatty acid or vitamin $\mathrm{D}_{3}$ tablets at comparable dosages had the option of going through an 8-week washout period before starting the trial. Participants who qualified were notified by the study coordinator and asked to obtain consent from their family physician to participate in the exercise intervention (Figure 1).

\section{Anthropomorphic measures}

Height was measured using a stadiometer (to the nearest $0.5 \mathrm{~cm}$ ). Body weight was measured using an electronic scale (to the nearest 0.05 $\mathrm{kg}$ ). Participants removed footwear but wore light clothing. Height and weight were used to calculate BMI. Waist and hip circumference was measured using a body measuring tape (to the nearest $0.5 \mathrm{~cm}$ ). Waist circumference was measured at the top of the iliac crest and hip circumference at the height of the greater trochanter. Measurements were completed upon screening (week 0 ) and weekly throughout the duration of the study (Table 1). All anthropomorphic measures were taken by the same study coordinator to ensure consistency between and within subjects.

\section{Resting heart rate and blood pressure}

Resting heart rate, and blood pressure (BP) were measured using an automated BP monitor (Omron IntelliSense ${ }^{\mathrm{Tw}}$ HEM-907XL;

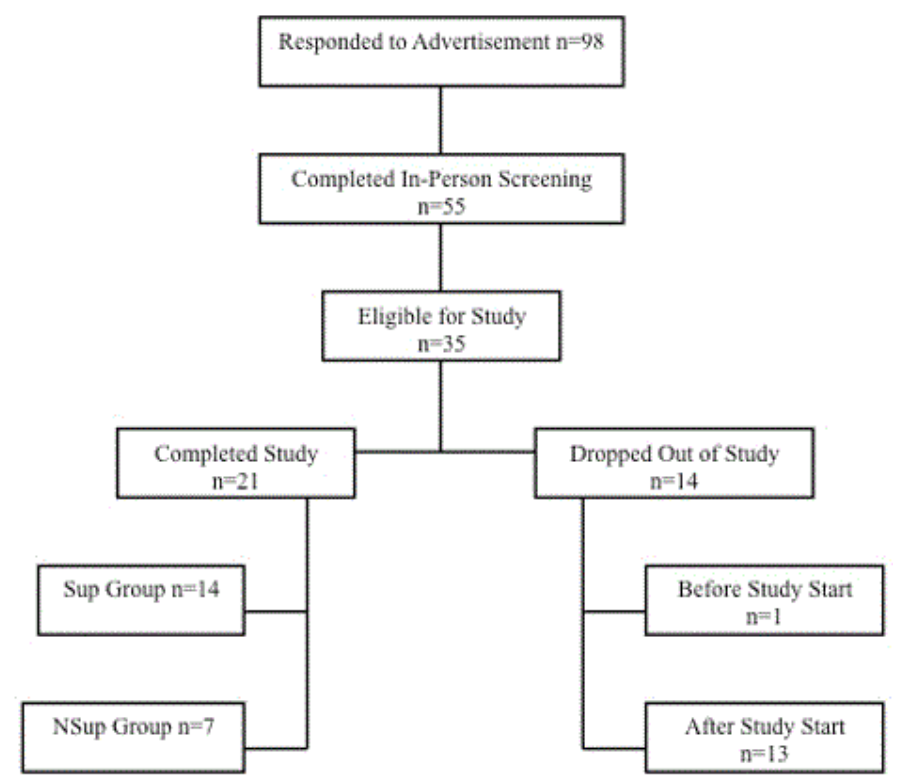

Figure 1. Flowchart of subject participation and withdrawal
Table 1. Schedule of data collection for study measurements.

\begin{tabular}{|c|c|c|c|c|c|}
\hline Weekly & Week 0 & Week 4 & Week 8 & Week 12 & Week 16 \\
\hline BW & Diet records & Diet records & Diet records & Diet records & Diet records \\
\hline BP & Glucose & & Glucose & & Glucose \\
\hline RHR & Insulin & & Insulin & & Insulin \\
\hline Waist & HbA1c & & HbA1c & & HbA1c \\
\hline Hip & Cholesterol & & Cholesterol & & Cholesterol \\
\hline & Serum TAG & & Serum TAG & & Serum TAG \\
\hline & Serum Vit D & & Serum Vit D & & Serum Vit D \\
\hline & RBC PL & & RBC PL & & RBC PL \\
\hline
\end{tabular}

BW: Body weight; BP: Blood pressure; RHR: Resting heart rate; HbA1c: Glycosylated hemoglobin, TAG: Triacylglycerol; HDL-Chol: High-density lipoprotein cholesterol; Vit D: 25-hydroxyvitamin $\mathrm{D}_{2} / \mathrm{D}_{3}$; RBC: Red blood cells; PL: Phospholipids

commercially available). Participants sat on an examination bed with arm resting at heart level for 5 minutes prior to measurement. Two readings separated by one-minute intervals were taken and averaged. Measurements were completed upon screening (week 0) and weekly throughout the duration of the study (Table 2).

\section{Blood collection}

All participants who came in for the in-person screening were asked to abstain from food or drink (except water) for 8-12 hours prior to coming in for their appointment. Blood was collected by venipuncture at the antecubital region of the arm by a certified phlebotomist. Blood was separated and sent to LifeLabs Medical Laboratory Services (Guelph, Ontario, Canada) for analysis of glucose, total cholesterol, HDL-cholesterol, triacylglycerol, insulin and HbAlc. Serum and RBCs were also retained in the lab and stored at $-80^{\circ} \mathrm{C}$ for later analysis of 25-hydroxyvitamin D and RBC plasma membrane phospholipid content. For participants who completed the study, blood was also collected at weeks 8 and 16 (end of study period) for analysis (Table 2).

\section{Study design \\ Participants}

Based upon the screening procedure, 35 participants qualified to participate in the research study. Participants were randomised to either the supplement intervention (Sup; $\mathrm{n}=17$ ) or to no supplement (NSup; $\mathrm{n}=18$ ). Those not receiving the intervention did not receive a placebo. Initially, 27 females and 8 males were recruited for the study. There was an attempt to maintain the ratio of male to female participants between groups equal while randomising into treatment groups, but more male participants dropped out of the non-supplemented group than the supplemented group by week 16 (final ratios: Nsup 6F:1M; Sup 10F:4M).

\section{Diet intervention}

Before starting the study, participants were given binders that contained information on the diet protocol, supplements, methods of measurement, exercise, and how to fill out records accurately. Participants also received instruction from assistant study coordinators on filling out diet records. Participants were required to fill out a 7-day food record prior to study commencement. This information was used to calculate baseline caloric consumption, average GI for foods consumed in a day, and macronutrient distribution.

At study commencement, participants were instructed to begin consuming foods according to the study protocol. Participants were instructed to consume macronutrients in the following percentage of total calories: $47 \%$ from carbohydrates, $30 \%$ from fat, and $23 \%$ from protein. Participants were also instructed to consume foods with 
Thomas RB (2017) Effect of a calorie-restricted, low-glycemic diet and exercise with omega-3 fatty acid and vitamin D supplementation on the risk of metabolic syndrome

Table 2. Baseline subject anthropomorphic characteristics

\begin{tabular}{|l|l|}
\hline Measurement & \multicolumn{2}{l|}{ Mean \pm SEM } \\
\hline Anthropomorphic & $101.4 \pm 4.3(\mathrm{n}=25)$ \\
\hline Body weight $(\mathrm{kg})$ & $36.4 \pm 1.4(\mathrm{n}=24)$ \\
\hline BMI $\left(\mathrm{kg} / \mathrm{m}^{2}\right)$ & $43.0 \pm 1.7(\mathrm{n}=25)$ \\
\hline Body fat $(\%)$ & $111.7 \pm 3.4(\mathrm{n}=25)$ \\
\hline Waist circumference $(\mathrm{cm})$ & $132.0 \pm 3.5(\mathrm{n}=17)$ \\
\hline Systolic blood pressure $(\mathrm{mm} \mathrm{Hg})$ & $91.6 \pm 3.4(\mathrm{n}=17)$ \\
\hline Diastolic blood pressure $(\mathrm{mm} \mathrm{Hg})$ & $76.5 \pm 1.9(\mathrm{n}=17)$ \\
\hline Resting heart rate (BPM) & \\
\hline Biochemical & $5.61 \pm 0.18(\mathrm{n}=21)$ \\
\hline Glucose (mmol/L) & $97.1 \pm 18.9(\mathrm{n}=20)$ \\
\hline Insulin (pmol/L) & $5.9 \pm 0.1(\mathrm{n}=21)$ \\
\hline HbA1c $(\%)$ & $5.05 \pm 0.24(\mathrm{n}=19)$ \\
\hline Cholesterol (mmol) & $1.21 \pm 0.01(\mathrm{n}=19)$ \\
\hline HDL-C (mmol) & $1.86 \pm 0.19(\mathrm{n}=19)$ \\
\hline Triacylglycerol (mmol) & \\
\hline
\end{tabular}

BMI: Body mass index; BPM: Beats per minute; HbA1c: Glycosylated hemoglobin HDL-C: High-density lipoprotein-cholesterol

a glycemic index of $<50 \%$ and to reduce total caloric intake by $25 \%$ compared to pre-study intake. All foods and beverages consumed in a day were recorded on daily diet records provided to participants.

Participants met weekly with assistant study coordinators where they returned completed diet records from the previous week and received new ones for the next week. These nutritional counseling meetings were used to help participants with compliance to the study protocol. Assistants reviewed participant diet records and entered the data into The Food Processor (Esha Research, Inc., Salem, OR, USA) to determine whether participants were meeting the study requirements and allowed assistant study coordinators to advise participants whether changes to their dietary choices were necessary. These meetings were also an opportunity for participants to express any concerns or ask questions. Records were analyzed for weeks $0,4,8,12$ and 16 to compare compliance over the duration of the study period (Table 2). Due to non-compliance by the NSup group to maintain adequate calorie restriction, we are only reporting the data from the first 8 weeks of the study.

\section{Exercise intervention}

All participants were required to participate in the exercise program at the University of Guelph Athletic Centre three times per week for the duration of the study. A circuit-training model was used consisting of alternating 12-15 repetitions of a resistance exercise followed by one minute of cardiovascular activity. The entire circuit was completed twice and took approximately one hour to accomplish. Typical exercises involved using equipment such as the chest press, leg press, dumbbells, Bosu balls and spin bicycles. The circuit was modified intermittently throughout the trial to break up the monotony of the exercise protocol.

During the initial visit to the Athletic Centre participants registered with the gym, and received instructions and orientation from the study coordinator who is also a certified personal trainer. Participants were shown proper use of the equipment and any additional questions were answered.

Target heart rates were calculated by the study coordinator using the Karvonen equation [31] and participants were instructed to exercise at $\sim 70 \%$ of their maximum heart rate. Heart rate monitors and wristwatches were used to monitor exertion. For the safety of the participants, the study coordinator ensured that correct form was used for exercises performed, that heart rates stayed within the prescribed range and that participants remained hydrated.

\section{Supplement intervention}

Participants in the supplementation group were instructed to consume 2 tablets (2000 IU total) of vitamin $\mathrm{D}_{3}$ (Jamieson Laboratories, Ltd., Windsor, ON, Canada) and 3 capsules (400 mg EPA/200 mg DHA per capsule, $1.8 \mathrm{~g}$ EPA+DHA total) of omega-3 fatty acids (Omega-3 Complete, Jamieson Laboratories, Ltd.) per day. Jamieson Laboratories, Ltd. donated all supplements. The dosage for omega- 3 fatty acids was the on-label recommendation and the dosage for vitamin $\mathrm{D}_{3}$ was higher than that listed on the label and was the highest dosage the research ethics board at the University of Guelph would allow. Compliance in supplement consumption was monitored by weighing the supplement bottle at each weekly counseling session.

\section{RBC phospholipid analysis}

Total red blood cell fatty acid composition was analyzed by a combination of lipid extraction and Gas Chromatographic techniques. Total lipid was extracted according to the methods of Bligh and Dyer [32]. The phospholipid fraction was separated from other lipids by thinlayer chromatography on silica gel plates (Fisher, Unionville, Ontario, Canada) in a solvent of chloroform/methanol/isopropanol/potassium chloride $(0.25 \% \mathrm{w} / \mathrm{w}) /$ triethanolamine (30:9:25:6:18). Phospholipids were scraped after visualization with $0.1 \%$ aminonaphtholsulfonic acid, and fatty acids were methylated (borontrifluoride-methanol) after addition of the fatty acid 17:0 as an internal standard. Methylated fatty acids were analyzed on an Agilent 7890A gas chromatograph equipped with flame ionization detection and separated on an DBFFAP fused-silica capillary column $(15 \mathrm{~m}, 0.1 \mu \mathrm{m}$ film thickness, 0.1 mm i.d.; Cat\# 127-32H2; Agilent Technologies, Santa Clara, CA, USA). Data were used to determine the degree of incorporation of EPA and DHA into RBC phospholipids and to measure compliance with the supplementation protocol.

\section{Vitamin D analysis}

Vitamin D was analysed using the 25-hydroxyvitamin D ${ }^{125} \mathrm{I}$ radioimmunoassay kit (kit\#68100E; DiaSorin Inc., Mississauga, ON, Canada). Serum samples frozen at $-80^{\circ} \mathrm{C}$ were thawed and used in the assay essentially as described in the manufacturer's instructions. The assay is a two-step procedure involving extracting hydroxylated metabolites (including $25(\mathrm{OH}) \mathrm{D}_{2} / \mathrm{D}_{3}$ ) and then assaying them. After extraction, samples were incubated with antibody and the ${ }^{125} \mathrm{I}$ tracer. After phase separation, the sample was precipitated with a second antibody precipitating complex. The liquid fraction of the samples was poured off and samples were dried. After drying was completed, samples were placed into a scintillation counter and activity was measured. Counts from samples and standards were recorded. This data was then transformed logarithmically to derive the $\mathrm{ng} / \mathrm{mL}$ concentration of $25(\mathrm{OH}) \mathrm{D}_{2} / \mathrm{D}_{3}$. Concentrations were converted into $\mathrm{nmol} / \mathrm{L}$.

\section{Statistics}

Statistics were performed using Microsoft Excel. A paired, twotailed, Student's t-test was used to determine within-group differences. An unpaired, two-tailed, Student's t-test was performed on the change in a given measure to compare the treatment effect between groups. Differences were considered significant at $\mathrm{p} \leq 0.05$. Specific participant data was omitted from analysis if they were taking medication or had a chronic illness that would affect a given measurement. Exact n-sizes are reported within each data table. 
Thomas RB (2017) Effect of a calorie-restricted, low-glycemic diet and exercise with omega-3 fatty acid and vitamin D supplementation on the risk of metabolic syndrome

\section{Results}

\section{Baseline participant characteristics}

In-person screening was completed with 55 potential participants, and of them, 35 were eligible to participate. One participant dropped out for unknown reasons prior to commencing the study. Of the 34 participants to begin the study, 4 dropped out as they felt they could not meet the time requirements of the study, 4 dropped out due to illness or injury (unrelated to the study), 2 dropped out due to family commitments, 1 moved out of the city and 2 left for unknown reasons (14 subjects total). Of the 21 subjects to complete the 8 weeks of the study, no subjects were removed for non-compliance. Participant characteristics at baseline are summarized in Table 2. The mean age of participants at the onset of the study was $46.7 \pm 2.6$ years. All participants met the International Diabetes Federation criteria for MetS (abdominal obesity plus two additional risk factors), with an average waist circumference of $111.7 \pm 3.4 \mathrm{~cm}$, an average systolic blood pressure of $132.0 \pm 3.5 \mathrm{mmHg}$, an average diastolic blood pressure of $91.6 \pm 3.4 \mathrm{mmHg}$ and an average serum triacylglycerol content of 1.86 $\pm 0.19 \mathrm{mmol} / \mathrm{L}$. However, neither blood glucose $(5.61 \pm 0.18 \mathrm{mmol} / \mathrm{L})$ nor HDL-cholesterol $(1.21 \pm 0.01 \mathrm{mmol} / \mathrm{L})$ met the cutoff values.

\section{Compliance}

All participants were required to modify their diet to maintain a specific macronutrient content ( $47 \% \mathrm{CHO}, 30 \%$ fat, $23 \%$ protein), reduce their total caloric intake by $\sim 25 \%$ and maintain a glycemic index consumption of $<50 \%$. Compliance was monitored using weekly food records. At baseline, diet composition and energy intake was not different between treatment groups. Compared to baseline, after 8 weeks, both groups had successfully reduced calorie consumption, with energy intake decreased by $-23.0 \%$ for NSup ( $\mathrm{p}=0.01$ compared to baseline) and $-17.8 \%$ for Sup ( $\mathrm{p}=0.03$ compared to baseline; $\mathrm{p}=0.66$ between treatment groups; Table 3 ). Diet composition was maintained within the recommendation throughout the study and was not different between groups or within groups at any time point measured (Table 3 ). The glycemic index throughout the study was an average of $42.5 \pm$ $1.6 \%$ for NSup and $42.5 \pm 1.3 \%$ for Sup. Unfortunately, by week 16 , diet records indicated that the NSup group had not been effectively calorie restricting their diet. Therefore, we are only reporting the 8 week data.

All subjects were also required to attend circuit-training sessions three times per week for the duration of the study. Compliance was measured as a percent of attended versus scheduled sessions. At the end of the 8-week treatment period, NSup subjects had completed $73 \pm 4 \%$ of their scheduled sessions and Sup had completed $75 \pm 4 \%$ ( $\mathrm{p}=0.865$ between groups).

Supplement compliance was measured weekly, by weighing the supplement bottle. Participant compliance in consuming the omega-3 supplement was excellent with an average of $100.5 \pm 0.9 \%$. Participant compliance in consuming the vitamin D supplement was also excellent with an average of $95.9 \pm 2.7 \%$.

\section{Effect of supplementation}

As both verification of supplementation compliance and to ensure a measurable effect of supplementation, red blood cell phospholipid EPA and DHA and serum vitamin D content were measured. In the non-supplement group, there were no differences in EPA, DHA or vitamin $\mathrm{D}$ between baseline and the end of the study period $(\mathrm{p}>0.05$; Table 4). In the supplement group, EPA increased from $0.81 \pm 0.11$ to $2.06 \pm 0.15 \mathrm{mmol} / \mathrm{L}(\mathrm{p}=0.0002 ; 2.85 \pm 0.30$ fold increase), DHA
Table 3. Diet characteristics

\begin{tabular}{|c|c|c|c|c|}
\hline \multirow{2}{*}{} & \multicolumn{2}{|c|}{ NSup } & \multicolumn{2}{c|}{ Sup } \\
\cline { 2 - 5 } & $\begin{array}{c}\text { BL } \\
(\mathbf{n = 9})\end{array}$ & $\begin{array}{c}\mathbf{W 8} \\
(\mathbf{n = 8})\end{array}$ & $\begin{array}{c}\text { BL } \\
(\mathbf{n = 1 4})\end{array}$ & $\begin{array}{c}\text { W8 } \\
(\mathbf{n = 1 3})\end{array}$ \\
\hline Energy (kcal) & $1624 \pm 116$ & $1253 \pm 73^{*}$ & $1599 \pm 137$ & $1315 \pm 98^{*}$ \\
\hline Carbohydrate (\% energy) & $44.3 \pm 2.7$ & $45.2 \pm 3.7$ & $47.7 \pm 1.1$ & $50.1 \pm 1.7$ \\
\hline Protein (\% energy) & $19.5 \pm 1.4$ & $23.1 \pm 1.4$ & $19.2 \pm 1.3$ & $21.8 \pm 1.2$ \\
\hline Fat (\% energy) & $36.2 \pm 2.2$ & $32.2 \pm 3.2$ & $33.0 \pm 1.4$ & $28.4 \pm 1.2$ \\
\hline
\end{tabular}

NSup: Non-supplemented group; Sup: Supplemented group; BL: Baseline measurement (week 0); W8: Week 8 measurement.

Values are means \pm SEM

"significantly different from baseline $(\mathrm{p}<0.05)$

Table 4. Red blood cell phospholipid composition and serum Vitamin D content with and without supplementation

\begin{tabular}{|c|c|c|c|c|}
\hline \multirow{2}{*}{} & \multicolumn{2}{|c|}{ NSup } & \multicolumn{2}{c|}{ Sup } \\
\cline { 2 - 5 } & $\begin{array}{c}\text { BL } \\
(\mathbf{n}=7)\end{array}$ & $\begin{array}{c}\text { W8 } \\
\mathbf{( n = 7 )}\end{array}$ & $\begin{array}{c}\text { BL } \\
(\mathbf{n = 1 4 )}\end{array}$ & $\begin{array}{c}\mathbf{W 8} \\
\mathbf{( n = 1 4 )}\end{array}$ \\
\hline EPA (mol \%) & $0.83 \pm 0.15$ & $0.88 \pm 0.20$ & $0.81 \pm 0.11$ & $2.06 \pm 0.15^{*}$ \\
\hline Fold $\boldsymbol{\Delta}$ & - & $1.05 \pm 0.11$ & - & $2.85 \pm 0.30$ \\
\hline DHA (mol \%) & $3.81 \pm 1.10$ & $4.10 \pm 0.35$ & $4.07 \pm 0.29$ & $5.18 \pm 0.25^{*}$ \\
\hline Fold $\boldsymbol{\Delta}$ & - & $1.08 \pm 0.05$ & - & $1.31 \pm 0.06$ \\
\hline Vit D (nmol/L) & $64.2 \pm 4.46$ & $68.4 \pm 3.32$ & $57.5 \pm 6.27$ & $79.2 \pm 2.54^{*}$ \\
\hline Fold $\boldsymbol{\Delta}$ & - & $1.07 \pm 0.05$ & - & $1.86 \pm 0.41$ \\
\hline
\end{tabular}

EPA: Eicosapentaenoic acid; DHA: Docosahexaenoic acid; Vit D: 25-hydroxyvitamin $\mathrm{D}_{2}$ / $\mathrm{D}_{3} ; \Delta$ : Change

Values are means \pm SEM

"significantly different from baseline $(\mathrm{p}<0.05)$

increased from $4.07 \pm 0.29$ to $5.18 \pm 0.25 \mathrm{mmol} / \mathrm{L}(\mathrm{p}=0.01 ; 1.31 \pm 0.06$ fold increase) and vitamin D increased from $57.5 \pm 6.27$ to $79.2 \pm 2.54$ $\mathrm{nmol} / \mathrm{L}$ ( $\mathrm{p}=0.054 ; 1.86 \pm 0.41$ fold increase).

\section{Anthropometry}

At baseline, there were no differences between the NSup and Sup groups for any anthropomorphic measure (Table 5). Following 8 weeks of calorie restriction, GI restriction and regular physical activity, body weight, BMI, waist and hip circumference and blood pressure decreased significantly from baseline in both the NSup and Sup group (summarized in Table 5). However, there was no difference in the magnitude of the decrease in any of the measures with omega- 3 fatty acid and vitamin D supplementation. Interestingly, resting heart rate was significantly decreased in the Sup group $(75.6 \pm 2.7$ to $69.5 \pm 2.2$ bpm; $\mathrm{p}=0.03$ ) but not in the NSup group.

\section{Biochemical markers}

At baseline, there were no differences between the NSup and Sup groups for any biochemical marker measured (Table 6). Following 8 weeks of calorie restriction, GI restriction and physical activity, there were no differences in fasting blood glucose, fasting insulin, HDLcholesterol or serum triacylglycerol levels in either the NSup or Sup group (summarized in Table 6). However, glycosylated hemoglobin levels were significantly reduced in the omega- 3 fatty acid and vitamin D supplemented group $(6.1 \pm 0.2 \%$ to $5.8 \pm 0.1 \%$; $\mathrm{p}=0.03)$, but not in the NSup group.

\section{Metabolic syndrome risk factors}

At the onset of this study, $100 \%$ participants were at risk for developing the Metabolic Syndrome (MetS) based on the criteria set out by the International Diabetes Federation. Following 8 weeks of calorie restriction, GI restriction and regular physical activity, only $58 \%$ of all participants were still at risk for MetS. Of those participants receiving omega-3 fatty acid and vitamin $\mathrm{D}$ supplementation, 64\% 
Thomas RB (2017) Effect of a calorie-restricted, low-glycemic diet and exercise with omega-3 fatty acid and vitamin D supplementation on the risk of metabolic syndrome

Table 5. Average anthropometric measures and average individual change from baseline

\begin{tabular}{|c|c|c|c|c|}
\hline & \multicolumn{2}{|c|}{ NSup } & \multicolumn{2}{|c|}{ Sup } \\
\hline & $\begin{array}{c}\text { BL } \\
(n=10)^{1}\end{array}$ & $\begin{array}{c}\text { W8 } \\
(n=10)\end{array}$ & $\begin{array}{c}\text { BL } \\
(n=14)^{2}\end{array}$ & $\begin{array}{c}W 8 \\
(n=14)\end{array}$ \\
\hline BW (kg) & $102.5 \pm 5.2$ & $98.7 \pm 4.9^{*}$ & $101.9 \pm 6.7$ & $98.7 \pm 6.8^{*}$ \\
\hline$\Delta B W(k g)$ & & $-3.8 \pm 0.9$ & & $-3.2 \pm 0.7$ \\
\hline BMI (kg/m²) & $36.0 \pm 1.8$ & $34.7 \pm 1.8^{*}$ & $36.7 \pm 2.0$ & $35.6 \pm 2.1^{*}$ \\
\hline$\Delta \mathrm{BMI}\left(\mathrm{kg} / \mathrm{m}^{2}\right)$ & & $-1.3 \pm 0.3$ & & $-1.2 \pm 0.3$ \\
\hline Waist circ (cm) & $109.9 \pm 4.7$ & $105.1 \pm 5.1^{*}$ & $114.4 \pm 4.8$ & $109.8 \pm 4.5$ \\
\hline $\begin{array}{c}\Delta \text { Waist circ } \\
(\mathrm{cm})\end{array}$ & & $-4.9 \pm 1.5$ & & $-4.6 \pm 1.3$ \\
\hline Hip circ (cm) & $123.9 \pm 4.6$ & $120.7 \pm 4.2^{*}$ & $125.1 \pm 4.1$ & $122.8 \pm 4.3$ \\
\hline$\Delta$ Hip circ (cm) & & $-3.3 \pm 1.3$ & & $-2.3 \pm 1.0$ \\
\hline $\begin{array}{l}\text { Syst BP } \\
(\mathbf{m m H g})\end{array}$ & $129.5 \pm 5.4$ & $121.8 \pm 4.6^{*}$ & $134.2 \pm 4.8$ & $128.1 \pm 5.0$ \\
\hline $\begin{array}{l}\Delta \text { Syst BP } \\
(\mathrm{mmHg})\end{array}$ & & $-7.8 \pm 2.4$ & & $-6.1 \pm 2.5$ \\
\hline $\begin{array}{l}\text { Diast BP } \\
\text { (mmHg) }\end{array}$ & $89.8 \pm 3.8$ & $80.3 \pm 3.3^{*}$ & $93.2 \pm 5.6$ & $81.9 \pm 4.4^{*}$ \\
\hline $\begin{array}{l}\Delta \text { Diast BP } \\
\text { (mmHg) }\end{array}$ & & $-9.5 \pm 1.1$ & & $-11.3 \pm 2.3$ \\
\hline RHR (BPM) & $77.5 \pm 2.8$ & $76.9 \pm 2.4$ & $75.6 \pm 2.7$ & $69.5 \pm 2.2^{*}$ \\
\hline$\Delta$ RHR (BPM) & & $-1.0 \pm 1.6$ & & $-5.9 \pm 2.5$ \\
\hline
\end{tabular}

NSup: Non-supplemented group; Sup: Supplemented group; BL: Baseline measurement (week 0); W8: Week 8; BW: Body weight; BMI: Body mass index; circ: Circumference; Syst: Systolic; Diast: Diastolic; BP: Blood pressure; RHR: Resting heart rate; BPM: Beats per minute; $\Delta$ : Change

Values are means \pm SEM

${ }^{1}$ Except BP and RHR measures $\mathrm{n}=8$

except BP and RHR measures $n=9$

significantly different from baseline $(\mathrm{p}<0.05)$

Table 6. Average biochemical measures and average individual change from baseline

\begin{tabular}{|c|c|c|c|c|}
\hline & \multicolumn{2}{|c|}{ NSup } & \multicolumn{2}{|c|}{ Sup } \\
\hline & $\begin{array}{c}\text { BL } \\
(n=9)\end{array}$ & $\begin{array}{c}\text { W8 } \\
(n=9)\end{array}$ & $\begin{array}{c}\text { BL } \\
(n=11)^{1}\end{array}$ & $\begin{array}{c}\text { W8 } \\
(n=11)\end{array}$ \\
\hline $\begin{array}{c}\text { Glucose } \\
(\mathrm{mmol} / \mathrm{L})\end{array}$ & $5.48 \pm 0.13$ & $5.26 \pm 0.10$ & $5.75 \pm 0.32$ & $5.65 \pm 0.24$ \\
\hline $\begin{array}{l}\Delta \text { Glucose } \\
(\mathrm{mmol} / \mathrm{L})\end{array}$ & & $-0.22 \pm 0.15$ & & $-0.10 \pm 0.32$ \\
\hline $\begin{array}{c}\text { Insulin } \\
\text { (pmol/L) }\end{array}$ & $107.9 \pm 34.9$ & $96.7 \pm 27.4$ & $84.5 \pm 21.8$ & $85.3 \pm 17.8$ \\
\hline $\begin{array}{l}\Delta \text { Insulin } \\
\text { (pmol/L) }\end{array}$ & & $-9.8 \pm 11.6$ & & $0.82 \pm 9.6$ \\
\hline HbA1c (\%) & $5.8 \pm 0.1$ & $5.7 \pm 0.1$ & $6.1 \pm 0.2$ & $5.8 \pm 0.1^{*}$ \\
\hline$\Delta$ HbA1c $(\%)$ & & $-0.06 \pm 0.1$ & & $-0.24 \pm 0.1$ \\
\hline $\begin{array}{c}\text { HDL-C } \\
(\mathrm{mmol} / \mathrm{L})\end{array}$ & $1.17 \pm 0.05$ & $1.15 \pm 0.06$ & $1.24 \pm 0.10$ & $1.18 \pm 0.09$ \\
\hline $\begin{array}{l}\Delta \text { HDL-C } \\
(\mathrm{mmol} / \mathrm{L})\end{array}$ & & $-0.04 \pm 0.05$ & & $-0.06 \pm 0.03$ \\
\hline TAG (mmol/L) & $1.95 \pm 0.33$ & $1.56 \pm 0.22$ & $1.75 \pm 0.25$ & $1.52 \pm 0.23$ \\
\hline$\Delta$ TAG mmol/L) & & $-0.37 \pm 0.23$ & & $-0.23 \pm 0.16$ \\
\hline
\end{tabular}

NSup: Non-supplemented group; Sup: Supplemented group; BL: Baseline measuremen (week 0); W8: Wek 8; HbA1c: Glycosylated hemoglobin; HDL-C: High-density lipoprotein-cholesterol; TAG: Tiacylglycerol; $\Delta$ : Change

except HDL-C and TG, $\mathrm{n}=9$

"significantly different from baseline $(\mathrm{p}<0.05)$

were still at risk, while of those not receiving supplementation, 50\% were still at risk (Figure 2).

\section{Discussion}

This 16-week pilot study was designed to determine whether, in the background of a diet and exercise program, omega-3 fatty acids and vitamin D supplementation could provide additional improvements to the risk factors of Metabolic Syndrome compared to the lifestyle intervention alone. We hypothesised that omega- 3 fatty acids and vitamin D supplementation would lead to greater weight loss and therefore a greater reduction in risk factors for MetS. Unfortunately, due to compliance issues, only data from the first 8 weeks is reported.

Participants were admitted into this study based on meeting the criteria for MetS [30]. Participants were considered within a risk factor if they reached the cutoff value, were diagnosed with a given medical condition and/or were being medicated for a given condition. The decision to include participants taking medication was in part to ensure that we could recruit sufficient participants, as it is unlikely to find subjects meeting these criteria who are not under the treatment of a physician. Additionally, this participant pool would be more representative of the population at large. However, this did require that certain participants be excluded from certain measures as their medications would confound the results and it would be unethical to request that participants stop taking medication during the study.

Of the 35 participants who were slated to start the study intervention, only 21 (or 60\%) completed the 8-week intervention. Although this is significant attrition, it is common for dietary and/or exercise interventions [5,33]. Surprisingly, twice as many participants dropped out of the non-supplemented cohort than the supplemented cohort. It is possible that since subjects were not blinded to whether or not they were taking the supplement, those not receiving the supplement could have perceived less of a benefit from the intervention. Other reasons for leaving the study included the amount of time required to complete the study, family obligations and injuries/illness not related to the study. However, there were no adverse effects related to the study design reported. There were many dietary restrictions as well as a significant time commitment for the exercise component of this study. It is possible that fewer participant requirements and/or increased oneon-one interactions with the participants could improve attrition rates in future studies.

Despite the number of participants who dropped out of the study, those who completed the 8-week intervention remained compliant to the study protocols. Diet records indicate that diet composition, glycemic index, and calorie restriction were all maintained within the study guidelines and was not different between treatment groups. Exercise compliance was $73-75 \%$ and not different between treatment groups. Compliance in supplement consumption among

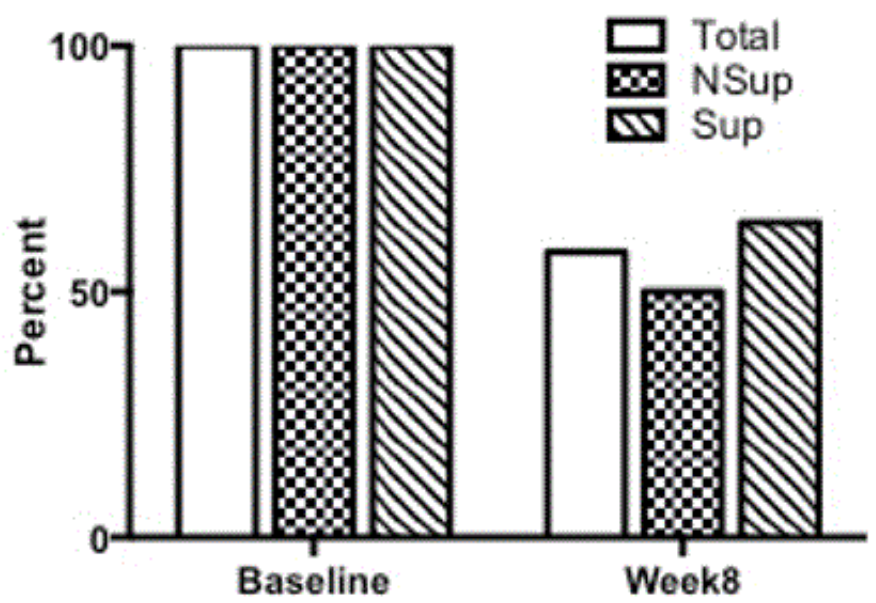

Figure 2. Subjects meeting the International Diabetes Federation definition of the Metabolic Syndrome. Percentage of participants pre-intervention and following 8 weeks of a diet and exercise intervention without (NSup=checked bars) or with ( $\mathrm{Sup}=$ lined bars) omega-3 and vitamin D supplementation (Total participant pool=white bar) 

syndrome

those receiving the supplement was $\sim 100 \%$ for both $\mathrm{n}-3$ fatty acids and vitamin D. Supplementation compliance was confirmed by RBC phospholipid and serum vitamin D analyses. This suggests that although there were many lifestyle factors that subjects had to control, those with the motivation to complete the study were able to maintain the lifestyle interventions for 8 weeks, however by 16 weeks, some subjects were unable to maintain the dietary restrictions and therefore this confounded our ability to specifically measure the benefits of the supplementation at this later time point. Many participants expressed that filling out daily diet records throughout the entire intervention was wearisome. Perhaps using less frequent records and/or moving to 3 -day records could improve the study design in the future.

The most important finding of this study is that a low GI, moderate protein, calorie-restricted diet combined with exercise is effective at reducing risk factors for MetS. Of the entire subject pool, $42 \%$ were no longer at risk following the 8-week intervention, however in the NSup group, this could only be attributed to changes in anthropomorphic measures. A significant decrease was observed in body weight, BMI, waist and hip circumference and both systolic and diastolic blood pressure. Similar improvements have previously been reported in obese women [5], however this study adds to the body of evidence in both men and women.

Interestingly, the supplemented group displayed two additional improvements not seen in the non-supplemented group. Both $\mathrm{HbAlc}$ and resting heart rate were slightly, but significantly lowered. While neither one of these measures is used to diagnose MetS, they are both indicative of improved metabolic health. HbAlc is considered the gold standard for measuring glycemic control $[34,35]$, as it is a measure of the previous 2-3 months' average glucose exposure [36]. A recent study demonstrated that daily supplementation with $2.7 \mathrm{~g}$ of $\mathrm{n}-3$ fatty acids in type 2 diabetics lead to a significant decrease in HbAlc [37], however a recent meta-analysis only demonstrated a trend [38]. Vitamin D has also been shown to decrease HbA1c in some studies [39,40], however current meta-analysis data fail to show a direct correlation between vitamin D and HbA1c [41,42]. Regardless, there is some evidence to suggest that $n-3$, vitamin $D$ or possibly the combination of the two supplements could be responsible for the decrease observed in this study. While resting heart rate (RHR) is not generally accepted as a therapeutic target [43], increased RHR has been observed in subjects with MetS [44] and is associated with increased morbidity in type 2 diabetic patients [45]. Meta-analysis has demonstrated a correlation between $\mathrm{n}-3$ supplementation and decreased RHR [46], which is believed to be due to a direct effect of the $n-3 s$ at the cardiomyocyte [47]. The data on vitamin $\mathrm{D}$ is more equivocal. A recent meta-analysis on vitamin $\mathrm{D}$ supplementation and cardiovascular risk in obese patients concludes that there is a paucity of intervention studies making correlating the two difficult [48]. While one research study demonstrated a negative correlation between vitamin D and RHR (as also seen in our study; [49]), another showed no difference following supplementation [50]. Clearly more investigation is required to determine the role of vitamin $\mathrm{D}$ and RHR, however, it is possible that our $\mathrm{n}-3$ supplementation could be responsible for the reduction in RHR observed in this study.

This pilot study demonstrates that a low glycemic index, moderate protein, calorie restricted diet combined with exercise can successfully reduce the risk factors of the metabolic syndrome by reducing anthropometric risk factors. Interestingly, supplementation of $n-3$ fatty acids and vitamin $\mathrm{D}$ in addition to this diet and exercise intervention resulted in decreased $\mathrm{HbAlc}$ levels and resting heart rate. Although not specifically risk factors for MetS, both indicate improvements in metabolic health. We recognize that our subject pool is small and therefore we might have been unable to detect other improvements due to a lack of statistical power. Additionally, due to our study design, we are unable to determine whether these improvements in the supplement group are due to the omega- 3 fatty acids, vitamin $\mathrm{D}$ or perhaps a synergistic effect of the combination of these two supplements. However, there is currently considerable interest in the health benefits of these two supplements both independently and combined. There is an ongoing prospective study, the vitamin D and omega-3 trial (VITAL), that is examining the effect of supplementation on cancer and cardiovascular risk in the general public [51,52]. Although risk of MetS is not the primary outcome measure, ancillary studies will be examining this disease as well. While it will be years before the results of VITAL will be published, our study demonstrates that omega-3 and vitamin D supplementation with respect to improving the health of subjects with MetS merits further investigation.

\section{Author contributions}

RT and AC performed experiments. RT, AC, LAS, and KMG analyzed data. RT and LAS wrote the manuscript. All authors edited and approved the final version of the manuscript.

\section{Acknowledgements}

The authors would like to acknowledge the technical support of the employees of the Human Nutraceutical Research Unit at the University of Guelph, specifically, Amy Tucker for helping to co-ordinate the site visits and Mehrnoosh Kashani for performing the phlebotomy. We also thank Megan Druet, Erin Ley, Katy Field, Ashley Weir and Season Wong for their assistance with the participants.

\section{Funding sources}

This work was not funded by any external funding source.

\section{Declarations}

The authors have no conflicts of interest to disclose.

\section{References}

1. O'Neill S, O'Driscoll L (2015) Metabolic syndrome: a closer look at the growing epidemic and its associated pathologies. Obes Rev 16: 1-12. [Crossref]

2. Alberti KG, Eckel RH, Grundy SM, Zimmet PZ, Cleeman JI, et al. (2009) Harmonizing the metabolic syndrome: a joint interim statement of the International Diabetes Federation Task Force on Epidemiology and Prevention; National Heart, Lung, and Blood Institute; American Heart Association; World Heart Federation; Internationa Atherosclerosis Society; and International Association for the Study of Obesity Circulation 120: 1640-1645. [Crossref]

3. Gallagher EJ, Leroith D, Karnieli E (2011) The metabolic syndrome--from insulin resistance to obesity and diabetes. Med Clin North Am 95: 855-873. [Crossref]

4. Grundy SM (2004) Obesity, metabolic syndrome, and cardiovascular disease. J Clin Endocrinol Metab 89: 2595-2600. [Crossref]

5. Campbell DD, Meckling KA (2012) Effect of the protein: carbohydrate ratio in hypo energetic diets on metabolic syndrome risk factors in exercising overweight and obese women. Br J Nutr 108: 1658-1671. [Crossref]

6. Meckling KA, Gauthier M, Grubb R, Sanford J (2002) Effects of a hypocaloric, lowcarbohydrate diet on weight loss, blood lipids, blood pressure, glucose tolerance, and body composition in free-living overweight women. Can J Physiol Pharmacol 80: 1095-1105. [Crossref]

7. Meckling KA, O'Sullivan C, Saari D (2004) Comparison of a low-fat diet to a lowcarbohydrate diet on weight loss, body composition, and risk factors for diabetes and cardiovascular disease in free-living, overweight men and women. J Clin Endocrinol Metab 89: 2717-2723. [Crossref]

8. Meckling KA, Sherfey R (2007) A randomized trial of a hypocaloric high-protein diet, with and without exercise, on weight loss, fitness, and markers of the Metabolic Syndrome in overweight and obese women. Appl Physiol Nutr Metab 32: 743-752. [Crossref] 
Thomas RB (2017) Effect of a calorie-restricted, low-glycemic diet and exercise with omega-3 fatty acid and vitamin D supplementation on the risk of metabolic syndrome

9. Brett KE, Meckling KA (2012) A Low Glycemic Index Diet Combined with an Aerobic-Resistance Exercise Program Reduces Risk Factors Associated with the Metabolic Syndrome. J Obes Weight Loss Ther 2: 8.

10. Levin BE (2007) Why some of us get fat and what we can do about it. $J$ Physiol 583: 425-430. [Crossref]

11. Esfahani A, Wong JM, Mirrahimi A, Srichaikul K, Jenkins DJ, et al. (2009) The glycemic index: physiological significance. $J$ Am Coll Nutr 28 Suppl: 439S-445S. [Crossref]

12. Radulian G, Rusu E, Dragomir A, Posea M (2009) Metabolic effects of low glycaemic index diets. Nutr J 8: 5. [Crossref]

13. Abete I, Astrup A, Martinez JA, Thorsdottir I, Zulet MA (2010) Obesity and the metabolic syndrome: role of different dietary macronutrient distribution patterns and specific nutritional components on weight loss and maintenance. Nutr Rev 68: 214-231.

14. Halton TL, Hu FB (2004) The effects of high protein diets on thermogenesis, satiety and weight loss: a critical review. J Am Coll Nutr 23: 373-385. [Crossref]

15. Clifton PM, Keogh JB, Noakes M (2008) Long-term effects of a high-protein weightloss diet. Am J Clin Nutr 87: 23-29. [Crossref]

16. MacLean PS, Higgins JA, Wyatt HR, Melanson EL, Johnson GC, et al. (2009) Regular exercise attenuates the metabolic drive to regain weight after long-term weight loss. $\mathrm{Am}$ J Physiol Regul Integr Comp Physiol 297: R793-R802. [Crossref]

17. Poirier P, Després JP (2001) Exercise in weight management of obesity. Cardiol Clin 19: 459-470. [Crossref]

18. Kelly RB (2010) Diet and exercise in the management of hyperlipidemia. Am Fam Physician 81: 1097-1102. [Crossref]

19. Saito Y, Yokoyama M, Origasa $H$, Matsuzaki M, Matsuzawa $Y$, et al (2008) Effects of EPA on coronary artery disease in hypercholesterolemic patients with multiple risk factors: sub-analysis of primary prevention cases from the Japan EPA Lipid Intervention Study (JELIS). Atherosclerosis 200: 135-140. [Crossref]

20. Woodman RJ, Mori TA, Burke V, Puddey IB, Watts GF, et al. (2002) Effects of purified eicosapentaenoic and docosahexaenoic acids on glycemic control, blood pressure, and serum lipids in type 2 diabetic patients with treated hypertension. Am J Clin Nutr 76: 1007-1015. [Crossref]

21. Rudkowska I (2010) Fish oils for cardiovascular disease: Impact on diabetes. Maturitas 67: 25-28. [Crossref]

22. Jung UJ, Torrejon C, Tighe AP, Deckelbaum RJ (2008) n-3 Fatty acids and cardiovascular disease: mechanisms underlying beneficial effects. Am J Clin Nutr 87: 2003S-2009S. [Crossref]

23. Abete I, Parra D, Crujeiras AB, Goyenechea E, Martinez JA (2008) Specific insulin sensitivity and leptin responses to a nutritional treatment of obesity via a combination of energy restriction and fatty fish intake. J Hum Nutr Diet 21: 591-600. [Crossref]

24. Poudyal H, Panchal SK, Diwan V, Brown L (2011) Omega-3 fatty acids and metabolic syndrome: effects and emerging mechanisms of action. Prog Lipid Res 50: 372-387. [Crossref]

25. Kim YS, Xun P, He K (2015) Fish consumption, long-chain omega-3 polyunsaturated fatty acid intake and risk of metabolic syndrome: a meta-analysis. Nutrients 7: 2085-2100.

26. Martini LA, Wood RJ (2006) Vitamin D status and the metabolic syndrome. Nutr $\operatorname{Rev}$ 64: 479-486. [Crossref]

27. Pittas AG, Lau J, Hu FB, Dawson-Hughes B (2007) The role of vitamin D and calcium in type 2 diabetes. A systematic review and meta-analysis. J Clin Endocrinol Metab 92: 2017-2029. [Crossref]

28. Afzal S, Bojesen SE, Nordestgaard BG (2013) Low 25-hydroxyvitamin D and risk of type 2 diabetes: a prospective cohort study and metaanalysis. Clin Chem 59: 381-391. [Crossref]

29. Chiu KC, Chu A, Go VL, Saad MF (2004) Hypovitaminosis D is associated with insulin resistance and beta cell dysfunction. Am J Clin Nutr 79: 820-825. [Crossref]

30. Alberti KG, Zimmet P, Shaw J (2006) Metabolic syndrome--a new world-wide definition. A Consensus Statement from the International Diabetes Federation. Diabet Med 23: 469-480. [Crossref]

31. Karvonen J, Vuorimaa T (1988) Heart rate and exercise intensity during sports activities. Practical application. Sports Med 5: 303-311. [Crossref]

32. Bligh EG, Dyer WJ (1959) A rapid method of total lipid extraction and purification. Can J Biochem Physiol 37: 911-917.
33. Larsen TM, Dalskov SM, van Baak M, Jebb SA, Papadaki A, et al. (2010) Diets with high or low protein content and glycemic index for weight-loss maintenance. $N$ Engl J Med 363: 2102-2113. [Crossref]

34. Ghazanfari Z, Haghdoost AA, Alizadeh SM, Atapour J, Zolala F (2010) A Comparison of HbA1c and Fasting Blood Sugar Tests in General Population. Int J Prev Med 1: 187-194. [Crossref]

35. Ketema EB, Kibret KT (2015) Correlation of fasting and postprandial plasma glucose with $\mathrm{HbA} 1 \mathrm{c}$ in assessing glycemic control; systematic review and meta-analysis. Arch Public Health 73: 43. [Crossref]

36. Monnier L, Colette C, Lapinski H, Boniface H (2004) Self-monitoring of blood glucose in diabetic patients: from the least common denominator to the greatest common multiple. Diabetes Metab 30: 113-119. [Crossref]

37. Toorang F, Djazayery A, Djalali M (2016) Effects of Omega-3 Fatty Acids Supplemen on Antioxidant Enzymes Activity in Type 2 Diabetic Patients. Iran J Public Health 45 : 340-345. [Crossref]

38. Chen C, Yu X, Shao S (2015) Effects of Omega-3 Fatty Acid Supplementation on Glucose Control and Lipid Levels in Type 2 Diabetes: A Meta-Analysis. PLoS One 10: e0139565. [Crossref]

39. Grubler MR, Gaksch M, Kienreich K, Verheyen N, Schmid J, et al. (2016) Effects of vitamin $\mathrm{D}$ supplementation on $\mathrm{HbAlc}$ and fasting glucose in hypertensive patients - a randomized controlled trial. Diabetes Obes Metab 18(10): 1006-1012. [Crossref]

40. Nikooyeh B, Neyestani TR, Farvid M, Alavi-Majd H, Houshiarrad A, et al. (2011) Daily consumption of vitamin D- or vitamin D + calcium-fortified yogurt drink improved glycemic control in patients with type 2 diabetes: a randomized clinical trial. Am J Clin Nutr 93: 764-771. [Crossref]

41. Seida JC, Mitri J, Colmers IN, Majumdar SR, Davidson MB, et al. (2014) Clinica review: Effect of vitamin D3 supplementation on improving glucose homeostasis and preventing diabetes: a systematic review and meta-analysis. J Clin Endocrinol Metab 99: 3551-3560. [Crossref]

42. George PS, Pearson ER, Witham MD (2012) Effect of vitamin D supplementation on glycaemic control and insulin resistance: a systematic review and meta-analysis. Diabet Med 29: e142-150. [Crossref]

43. Fox K, Borer JS, Camm AJ, Danchin N, Ferrari R, et al. (2007) Resting heart rate in cardiovascular disease. J Am Coll Cardiol 50: 823-830. [Crossref]

44. Rana JS, Hardison RM, Pop-Busui R, Brooks MM, Jones TL, et al. (2010) Resting heart rate and metabolic syndrome in patients with diabetes and coronary artery disease in bypass angioplasty revascularization investigation 2 diabetes (BARI 2D) trial. Prev Cardiol 13: 112-116. [Crossref]

45. Linnemann B, Janka HU (2003) Prolonged QTc interval and elevated heart rate identify the type 2 diabetic patient at high risk for cardiovascular death. The Bremen Diabetes Study. Exp Clin Endocrinol Diabetes 111: 215-222. [Crossref]

46. Mozaffarian D (2005) Does alpha-linolenic acid intake reduce the risk of coronary hear disease? A review of the evidence. Altern Ther Health Med 11: 24-30. [Crossref]

47. Kang JX (2012) Reduction of heart rate by omega-3 fatty acids and the potential underlying mechanisms. Front Physiol 3: 416.

48. Manousopoulou A, Al-Daghri NM, Garbis SD, Chrousos GP (2015) Vitamin D and cardiovascular risk among adults with obesity: a systematic review and metaanalysis. Eur J Clin Invest 45: 1113-1126. [Crossref]

49. Scragg RK, Camargo CA Jr, Simpson RU (2010) Relation of serum 25-hydroxyvitamin D to heart rate and cardiac work (from the National Health and Nutrition Examination Surveys). Am J Cardiol 105: 122-128. [Crossref]

50. Gepner AD, Ramamurthy R, Krueger DC, Korcarz CE, Binkley N, et al. (2012) A prospective randomized controlled trial of the effects of vitamin $\mathrm{D}$ supplementation on cardiovascular disease risk. PLoS One 7: e36617.

51. Manson JE, Bassuk SS, Lee IM, Cook NR, Albert MA, et al. (2012) The VITamin D and OmegA-3 TriaL (VITAL): rationale and design of a large randomized controlled trial of vitamin D and marine omega-3 fatty acid supplements for the primary prevention of cancer and cardiovascular disease. Contemp Clin Trials 33: 159-171. [Crossref]

52. Pradhan AD, Manson JE (2016) Update on the Vitamin D and OmegA-3 trial (VITAL). J Steroid Biochem Mol Biol 155: 252-256. [Crossref]

Copyright: (C) 2017 Thomas RB. This is an open-access article distributed under the terms of the Creative Commons Attribution License, which permits unrestricted use, distribution, and reproduction in any medium, provided the original author and source are credited. 